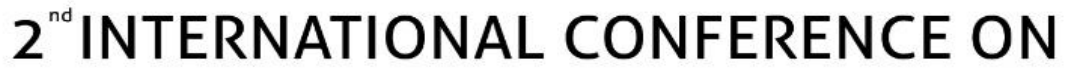 \\ FUTURE OF TEACHING \& EDUCATION
}

Munich,Germany

6 - 8 December,2019

\section{Burnout among tertiary level EFL instructors}

\author{
Dr.Emrah Cinkara \\ Gaziantep University, Faculty of Education
}

\begin{abstract}
Burnout is a psychological syndrome which is sustained response to chronic social stressors on the job and teachers are one of the most probable occupational groups to have burnout syndrome because they have always a lot of people around themselves to take care and be responsible about. Teachers are one of the most important factors in educational process. Having eager and determined teachers will make teaching process be effective as much as possible. The purpose of this study was to investigate the relationship between burnout and demographic features of English teachers. In data collection, Maslach Burnout Inventory- Educators Survey was used to identify burnout levels of English teachers. It was revealed that English teachers in Gaziantep experience from high to extreme level of burnout. Also, between age and burnout level of English teachers, there was no significant relation. In terms of gender variable, there was also no significant relation except that male participants had slightly higher level than female participants.
\end{abstract}

Keywords: Burnout; EFL instructors, language teaching 